\title{
Early Hospital Discharge and Early Puerperal Complications
}

\author{
Zahia Saad Elghazal ${ }^{1 *}$, Fatma Abdullah Emtawel ${ }^{1}$ and Ekram Barakat Ben \\ Sauod $^{2}$ \\ ${ }^{1}$ Department of Gynecology \& Obstetrics, Faculty of Medicine, University of Benghazi-Libya. \\ ${ }^{2}$ Department of Family and Community Medicine, Faculty of Medicine, University of Benghazi- \\ Libya.
}

Received: 22 November 2020/ Accepted: 30 December 2020

Doi: https://doi.org/10.54172/mjsc.v35i4.333

\begin{abstract}
The study aimed to evaluate the association between the time of postpartum discharge and symptoms indicative of complications during the first postpartum week. The cross-sectional study included 753 women with vaginal delivery at Al-Jamhorya teaching public hospital without complications were interviewed before the hospital discharge and seven days after. The time of postpartum discharge was classified as early ( $\leq 24$ hours) or late ( $>24$ hours). A total of 753 mothers were enrolled in the study. The majority (94.3\%) of the mothers stayed in the hospital $\leq 24$ hours, $4.1 \%>24$ hours, and $1.6 \%$ were discharged against medical advice. The mean duration of hospital stay was $12.1 \pm 6.1$ hours, with a minimum hospital stay of 2 hours and a maximum stay of 46 hours. The prenatal care was satisfactory in $91.2 \%$. Prenatal care was satisfactory in $91 \%$ of early discharge mothers and $93.5 \%$ in the late group. This slight difference was not statistically significant. After delivery, $8.4 \%$ had urinary tract infections. Urinary tract infection after delivery occurred in $8.2 \%$ of mothers with early discharge and $12.9 \%$ in mothers with late discharge. This difference was not statistically significant. Complications of episiotomy were recorded in $79.9 \%$ of mothers with early discharge and $61.3 \%$ in late discharge. This difference was statistically significant. The study's conclusions indicated that late discharge mothers had received anesthesia and performed episiotomy more than early discharge mothers. Complications of episiotomy were recorded more in mothers with early discharge than in late discharged mothers. It is recommended that a randomized clinical trial is best to evaluate the association between the time of discharge postpartum and the presence of complications, also to attain safety and possible benefits of shorter hospital stay.
\end{abstract}

Keywords: Early Hospital Discharge, Vaginal Delivery, Puerperal Complications

\section{INTRODUCTION}

Maternal morbidity refers to complications that have arisen during the pregnancy, delivery, or postpartum period. Every year an estimated 50 million women are affected by maternal morbidity. Defining, interpreting, and measuring maternal morbidity, however, is recognized to be difficult, and the prevalence of such morbidity (both general and specific) has been poorly described.(Fortney \& Smith, 1999; Organization, 1998). Over the past decade, the nature and extent of postpartum maternal morbidity have received increasing interest in both developed and developing countries, with a range of research methods of varying sophistication being used to identify long and short-term and acute and chronic morbidity following childbirth. (Fikree et al., 2004; M. Chama, 2000;

*Corresponding Author: Zahia Saad Elghazal zahia.elghazal@uob.edu.ly, Department of Gynecology \& obstetrics , Faculty of Medicine, university of Benghazi-Libya. 
Organization, 1998; Silverton, 1993; Waterstone et al., 2003).

The WHO (1998) defines the postpartum period, or puerperium, as beginning one hour after the delivery of the placenta and continuing until 6 weeks (42 days) after the birth of the infant.(Organization, 1998). As the woman recovers from labour, adapts to her new role, and reverts physically to her nonpregnant state, it is an exceptional but critical time for both the mother and her infant (Cunningham F, 2001).

Many of the complications leading to postpartum maternal morbidity arise during labor and delivery and in the first 1-2 weeks following delivery; for at least 18 million women, these morbidities become long-term and are often debilitating. Major acute obstetric morbidities include haemorrhage, sepsis, and pregnancy-related hypertension. Longer-term morbidities include uterine prolapse, vesicovaginal fistulae, incontinence, dyspareunia, and infertility (Koblinsky \& Tinker, 1994).

Fortney \& Smith have described six dimensions to maternal morbidity: etiology, severity, duration, time of onset, accumulation, and sequelae. However, in many developing countries, health services data on postpartum morbidity remains extremely limited. In recent years, there has been growing interest to determine the ideal time for postpartum discharge for optimal maternal and child outcomes. (Fikree et al., 2004; M. Chama, 2000; Organization, 1998; Silverton, 1993; Waterstone et al., 2003). Hospital length of stay after childbirth has decreased progressively during the past 60 years. (Braveman et al., 1996; Koblinsky \& Tinker, 1994; Madden et al., 2002). In the early 1980s in Mexico, the Mexican Social Security Institute developed the program Atención de Parto de Bajo Riesgo (Care for Low-Risk Delivery), which resulted in a six-hour reduction in postpartum hospital stays. (Britton et al., 1994; Yaffe et al., 2001).
For women who have uncomplicated vaginal deliveries, the American College of Obstetrics and Gynecology (ACOG) defines early discharge as a hospital stay lasting 48 hours or less and considers a stay of 24 hours or less as very early discharge (VED). (Hellman et al., 1962; Lieu et al., 2000; Norr \& Nacion, 1987). This study hypothesizes that shorter postpartum stays are associated with poor health outcomes because of the decreased probability of detecting postpartum complications, as has been found in studies with other populations (Norr \& Nacion, 1987).

Objective: To evaluate the association between the time of postpartum discharge and symptoms indicative of complications during the first postpartum week.

\section{MATERIAL AND METHODS}

Study Subjects and Setting: 753 women with vaginal delivery at Al-Jamhorya teaching public hospital without complication were interviewed before the hospital discharge, and seven days after the Time of postpartum discharge, which was classified as early ( $\leq 24$ hours) or late ( $>24$ hours).

Study sample: (A convenient sample of 753 Women).

Study duration: The study was conducted during a period of 6 months, from January 2014 to June 2014.

Inclusion criteria: a) vaginal delivery of a live singleton term infant (gestational age 37 to 41 weeks); b) uncomplicated pregnancy without concomitant diseases such as diabetes, hypertension, preeclampsia, cardiopathy, epilepsy, or evident infections; and c) residence in Benghazi City.

The exclusion criteria were refusal to participate, and residing outside the city. The withdrawal criteria were failure to locate the patient after three attempts. 
Four trained interviewers evaluated medical records to select subjects who fulfilled the inclusion criteria and then invited eligible mothers to participate in the study.

To collect the following baseline data, selected mothers were asked to participate in a face-to-face interview before leaving the hospital: a) socio-demographic characteristics; b) gynecologic and obstetric history; c) prenatal care assessed; d) delivery events, including vaginal lacerations; and e) clinical characteristics of the immediate puerperium, (considered as the 24 hours following delivery). A chart review was performed for all cases to corroborate questionnaire data and obtain clinical information. Information about the time of discharge was retrieved from medical records after discharge. Mothers were invited for a medical visit seven days after delivery, at this visit, mothers underwent another face-to-face interview to obtain information related to maternal postpartum health. Mothers who failed to attend the 7-day follow-up appointment, would be considered as lost to follow up.

The study outcome variable was the presence of self-reported symptoms in early puerperium. This variable was measured using symptoms reported by the mother during an interview conducted seven days after hospital discharge. Symptoms were categorized as suggestive of a) urinary tract infection (dysuria, frequent urination, bladder tenesmus); b) episiotomy complications (local pain or discomfort, bleeding, separation of sutures, c) episiotomy infection (purulent discharge, pain, warmth, and redness in the area); d) endometritis: (uterine pain, foul-smelling lochia, and fever or shivering); f) mastitis and/or mammary abscess (pain, heat, and redness or cracking of nipples); and g) other reported symptoms or hospital readmission.

Statistical analysis: Data were analyzed using a statistical package for social science (SPSS) version 18. Descriptive statistics, such as mean, standard deviation, median and mode were used. Inferential statistics were used when needed, as Chi-square $\left(\mathrm{x}^{2}\right)$ to find the difference in the distribution of the variables between the two groups, P-value was considered significant when $\leq 0.05$. Data were presented in tables and figures, which were the figures done by Microsoft Excel 2003.

\section{RESULTS}

The majority of women (54\%) were in the age group between 21-30 years followed by 31-40 years old, as shown in figure 1 .

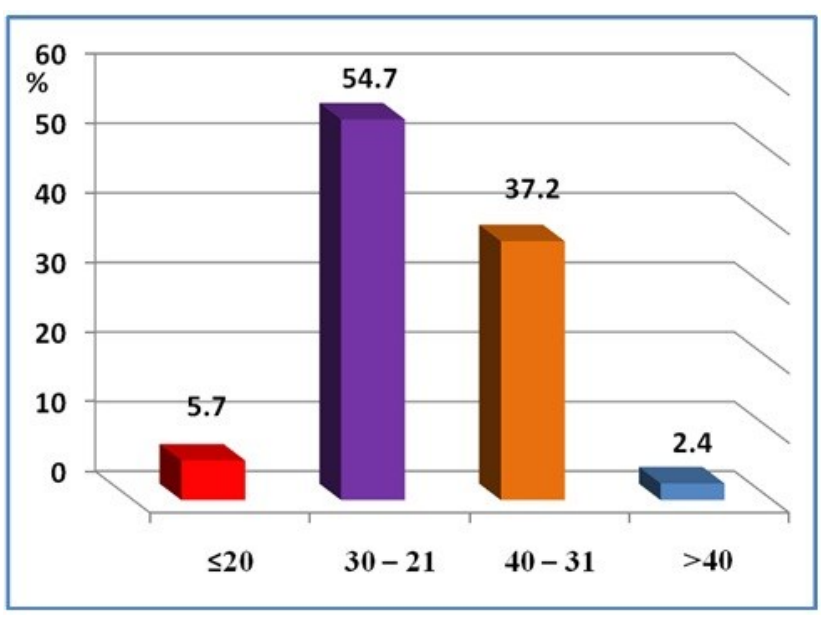

Figure (1): Distribution of mothers according to age (years).

Table (1): Distribution of mothers according to their level of education.

\begin{tabular}{lcc}
\hline \hline Level of education & No. & $\%$ \\
\hline Illiterate & 14 & 1.9 \\
Primary School & 85 & 11.3 \\
Preparatory School & 399 & 53 \\
Secondary School & 251 & 33.3 \\
University & 4 & 0.5 \\
Total & 753 & 100 \\
\hline \hline
\end{tabular}

The Relationship between duration of hospital stay (hours) and type of anesthesia $\mathrm{X}^{2}=8.906 \mathrm{df}=2 ; \mathrm{p}=0.012$ (Significant) according to (table 2 ). 
Table (2): Distribution of mothers according to time of postpartum hospital discharge and type of anesthesia.

\begin{tabular}{lllllll}
\hline \hline \multirow{2}{*}{\begin{tabular}{l} 
Type of $\begin{array}{r}\text { of } \\
\text { anesthesia }\end{array}$ \\
\cline { 2 - 5 }
\end{tabular}} & $\begin{array}{l}\text { Duration of hospital } \\
\text { (hours) }\end{array}$ & \multicolumn{3}{c}{ stay } & Total \\
\cline { 2 - 5 } & \multicolumn{2}{c}{$\leq 24$} & \multicolumn{2}{c}{$>24$} & \\
\hline Local & $\%$ & No. & $\%$ & No. & $\%$ \\
Not given & 224 & 31.5 & 2 & 6.5 & 226 & 30.5 \\
Epidural & 1 & 0.1 & 0 & 0 & 1 & 0.1 \\
Total & 710 & 100 & 31 & 100 & 741 & 100 \\
\hline \hline
\end{tabular}

The relationship between the time of postpartum hospital discharge and prenatal care: (Prenatal care was satisfactory in $91.2 \%$, where only $8.8 \%$ of the cases were unsatisfactory). Prenatal care was satisfactory in $91 \%$ of early discharge and $93.5 \%$ in the late group: e. $\mathrm{X}^{2}=0.240 \mathrm{df}=1 ; \mathrm{p}=0.624$, and this slight difference was not statistically significant (Not Significant). The relationship between time of postpartum hospital discharge and vaginal laceration: $p=0.174$ (Not significant) according to information as shown in (table 3).

Table (3): Distribution of mothers according to complications.

\begin{tabular}{llll}
\hline \hline Complications & Details & No. & Percent $\%$ \\
\hline Vaginal laceration & Yes & 113 & $15 \%$ \\
& No & 640 & $85 \%$ \\
Urinary tract infec- & Yes & 63 & $8.4 \%$ \\
tion (after delivery) & No & 620 & $82.3 \%$ \\
History of Thrombo- & Yet known & 70 & $9.3 \%$ \\
embolic complica- & No & 6 & $0.8 \%$ \\
tion( after delivery) & Not known & 72 & 9.6 \\
\hline \hline
\end{tabular}

After delivery, $8.4 \%$ had urinary tract infections. Urinary tract infection after delivery has occurred in $8.2 \%$ of mothers with early discharge and $12.9 \%$ in mothers with late discharge, this difference was not statistically significant. Late discharge mothers had received anesthesia and performed episiotomy more than early discharge mothers. A complication of episiotomy was recorded more in mothers with late discharge than in early discharged mothers as shown in (figure 2).

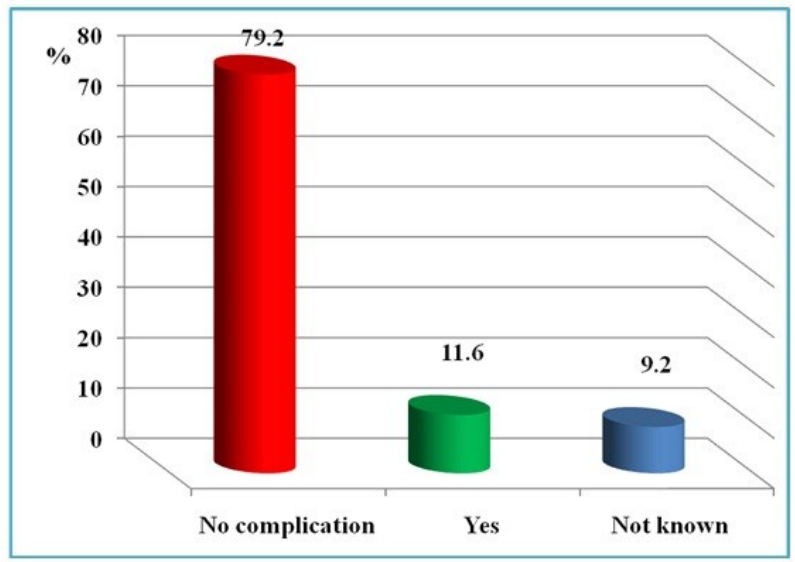

Figure (2): Distribution of mothers according to complications of episiotomy.

From this study, it was observed that pain and infection were recorded in mothers with late discharge more than early discharge. The pain constituted $62.5 \%$ in the late group, as shown in (table 4), and $45.9 \%$ in the early group. The infection was recorded in $25 \%$ of the late group and only $8.1 \%$ of the early group, as observed in (table 4).

Table (4): Relationship of mothers according to time of postpartum hospital discharge and type of complications of episiotomy.

\begin{tabular}{|c|c|c|c|c|c|c|}
\hline \multirow{3}{*}{$\begin{array}{l}\text { Types of epi- } \\
\text { siotomy } \\
\text { complications }\end{array}$} & \multicolumn{4}{|c|}{ No. } & \multirow{2}{*}{\multicolumn{2}{|c|}{ Total }} \\
\hline & \multicolumn{2}{|l|}{$\leq 24$} & \multicolumn{2}{|l|}{$>24$} & & \\
\hline & No. & $\%$ & No. & $\%$ & No. & $\%$ \\
\hline Pain & 34 & 45.9 & 5 & 62.5 & 39 & 47.6 \\
\hline $\begin{array}{l}\text { Pain \& red- } \\
\text { ness }\end{array}$ & 25 & 33.8 & 1 & 12.5 & 26 & 31.7 \\
\hline Infection & 6 & 8.1 & 2 & 25 & 8 & 9.8 \\
\hline $\begin{array}{l}\text { Separation of } \\
\text { suture }\end{array}$ & 6 & 8.1 & 0 & 0 & 6 & 7.3 \\
\hline $\begin{array}{l}\text { Redness in } \\
\text { the area }\end{array}$ & 3 & 4.1 & 0 & 0 & 3 & 3.6 \\
\hline Total & 74 & 100 & 8 & 100 & 82 & 100 \\
\hline
\end{tabular}

Complications of episiotomy were recorded in $79.9 \%$ of mothers with early discharge and $61.3 \%$ in late discharge. This difference was statistically significant. Relationship between time of postpartum hospital discharge and mastitis after delivery: $\mathrm{X}^{2}=1.468 \mathrm{df}=2$; $\mathrm{p}=0.480$. (Not significant) according to the 
information from (figure 3).

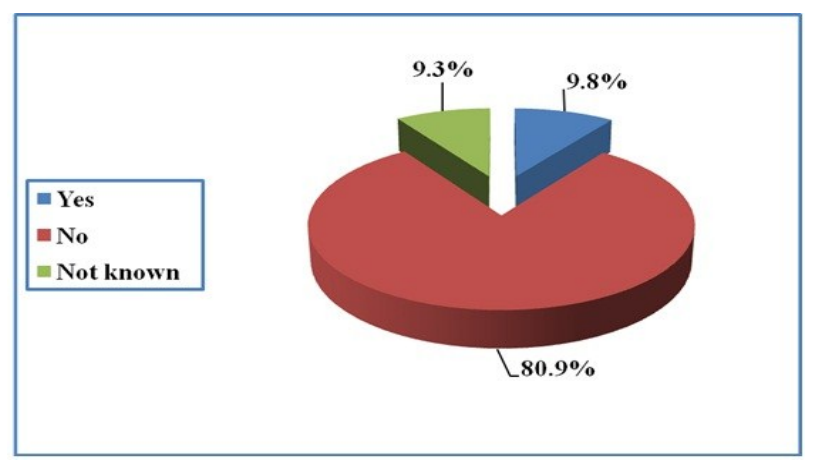

Figure (3): Distribution of mothers according to the history of mastitis after delivery.

Furthermore, in the following table, we demonstrate the difference in early and late discharge according to many variables with mean and standard deviation all of which are recorded in table 5 .

Table (5): Characteristics describing mothers studied according to time of postpartum hospital discharge, Al-Jamhorya Hospital, Benghazi.

\begin{tabular}{|c|c|c|}
\hline Variable & $\begin{array}{l}\text { Early discharge } \\
(\leq 24 \mathrm{hrs}) \mathrm{n}(\%)\end{array}$ & $\begin{array}{l}\text { Late discharge } \\
(>24 \mathrm{hrs}) \mathrm{n}(\%)\end{array}$ \\
\hline $\begin{array}{l}\text { Duration of hospital } \\
\text { stay }\end{array}$ & $\begin{array}{l}\text { Mean } \pm \text { St.Dev. } \\
11.4 \pm 5.2\end{array}$ & $\begin{array}{l}\text { Mean } \pm \text { St.Dev. } \\
27 \pm 4.5\end{array}$ \\
\hline $\begin{array}{l}\text { Obstetric history } \\
\text { Satisfactory } \\
\text { Unsatisfactory }\end{array}$ & $\begin{array}{l}646(91) \\
64(9)\end{array}$ & $\begin{array}{l}29(93.5) \\
2(6.5)\end{array}$ \\
\hline $\begin{array}{l}\text { Status of the patient at } \\
\text { the time of admission } \\
\text { Second stage } \\
\text { Ruptured membranes }\end{array}$ & $\begin{array}{l}97(13.7) \\
189(26.6)\end{array}$ & $\begin{array}{l}3(9.7) \\
8(25.8)\end{array}$ \\
\hline Procedures & & \\
\hline Labour induction & $189(26.6)$ & $8(25.8)$ \\
\hline Application of enema & $0(0)$ & $0(0)$ \\
\hline Episiotomy & $406(57.2)$ & $27(87.1)$ \\
\hline $\begin{array}{l}\text { Bladder catheter at the } \\
\text { time of delivery } \\
\text { Yes } \\
\text { Type of anesthesia }\end{array}$ & $412(58)$ & $21(67.7)$ \\
\hline None & $224(31.5)$ & $2(6.50$ \\
\hline Local & $485(68.4)$ & $28(93.5)$ \\
\hline Epidural & $1(0.1)$ & $0(0)$ \\
\hline
\end{tabular}

\section{DISCUSSIONS}

A total of 753 mothers were enrolled in the study. The majority (94.3\%) of the mothers stayed in the hospital $\leq 24$ hour, $4.1 \%$ $>24$ hours, and $1.6 \%$ were discharged against medical advice.

The mean duration of hospital stay was $12.1 \pm 6.1$ hours, with a minimum hospital stay of two hours and a maximum stay of 46hours. Another study conducted by Dolores RV in Mexico 2009 recorded that $68.6 \%$ had early postpartum discharge, with a mean hospital stay of $21.5 \pm 8.5$ hours. The study also showed that although there was no association between early discharge and the severity of complications during early puerperium for all mothers, the presence of symptoms decreased among women who received indications to have a medical checkup one week later. Symptoms also decreased among women with early discharge and satisfactory prenatal care, compared with those with early discharge and unsatisfactory prenatal care, suggesting a positive effect of adequate prenatal care even with an early discharge. This correlation deserves further study to better understand its importance. Consequently, the researchers concluded that there was no association between early discharge and symptoms of complications during the first postpartum week; the odds of complications were lower for mothers with early discharge and satisfactory prenatal care (RamírezVillalobos et al., 2009).

The results of the current study showed that prenatal care was satisfactory in $91.2 \%$. Prenatal care was satisfactory in $91 \%$ of early discharge and $93.5 \%$ in the late group and this slight difference was not statistically significant $\mathrm{p}=0.624$, and the mean age of mothers was $29.4 \pm 5.8$ years, with a minimum age of 15 years and a maximum of 43 years. A majority $(91.9 \%)$ was in the age group between 21 years to 40 years. Furthermore, the age of mothers with an early discharge was similar to those with a late discharge, and there was no statistical difference between the two groups $\mathrm{p}=0.838$. This result was similar to 
other studies. (Ramírez-Villalobos et al., 2009)

In this study, the complications of episiotomy were recorded in $11.6 \%$ of the patients. The complication of episiotomy was recorded in $79.9 \%$ of mothers with early discharge and $61.3 \%$ in late discharge. This difference was statistically significant $\mathrm{p}=0.027$.

Furthermore, readmission to the hospital after delivery was recorded in 4 mothers $(0.5 \%)$, and all of them were in the early discharge group. In other studies, no significant differences were found in the rates of maternal rehospitalization $(1.9 \%$ in the early discharge group vs. 2.3\% in the control group) (Bueno et al., 2005).

In this study, an episiotomy was done in $57.2 \%$ of early discharge cases and $87.1 \%$ in those with a late discharge. This difference was statistically significant $p=0.001$. A bladder catheter was done during labour to $58 \%$ of mothers with early discharge and $67.7 \%$ in late discharge. This difference was not statistically different $(\mathrm{p}=0.283)$.

Whereas, a case-control study in India 2015 reported that: the younger mothers who had first time accessed antenatal services and who had less than three ANC visits during the antenatal period, and mothers delivering in government hospitals in addition to not having any complications during delivery, and those who requested early discharge, and were discharged within $48 \mathrm{~h}$ of delivery, were more likely to have discharged early from hospitals, in addition to lack of insistence by doctors against early discharge.

The normal condition of mothers, babies, and multiparous mothers were the main reasons for early discharge as perceived by the health care providers. It is important to design appropriate strategies to ensure timely discharge, and they should have local level acceptance. (Nipte et al., 2015)
The current study's findings demonstrated that $8.4 \%$ of mothers after delivery had urinary tract infections. Urinary tract infection after delivery has occurred in $8.2 \%$ of mothers with early discharge and $12.9 \%$ in mothers with late discharge. This difference was not statistically significant, $\mathrm{p}=0.483$, this result was similar to the result of other studies (Ramírez-Villalobos et al., 2009). The complication of episiotomy was recorded in $11.6 \%$ of the patients. A complication of episiotomy was recorded in $79.9 \%$ of mothers with early discharge and $61.3 \%$ in late discharge, this difference was statistically significant $\mathrm{p}=0.027$.

Pain at the episiotomy site was recorded in $46 \%$ of the mothers, pain, and redness in $32.2 \%$, infection in $10.3 \%$, separation of the suture in $8 \%$, and redness in $3.5 \%$. Pain and infection were recorded in mothers with late discharge more than early discharge. The pain constituted $62.5 \%$ in the late group, and $45.5 \%$ in the early group. The infection was recorded in $25 \%$ of the late group and only $9.1 \%$ of the early group.

History of mastitis was positive in $9.8 \%$ of the patients. Mastitis after delivery was recorded in $9.7 \%$ of mothers with early discharge and $16.1 \%$ in mothers with late discharge. This difference was not statistically significant $\mathrm{p}=0.480$.

History of thromboembolic complication after delivery was positive in six mothers $(0.8 \%)$, and all of them were in the early discharge group. The causes of early discharge of mothers from hospital after delivery could be explained by various reasons such as dissatisfaction about hospital accommodation or care, need to take care of other children at home, feeling more comfortable at home, and no beds in the hospital. The results of the Indian study of early discharge among mothers who delivered in government hospitals, are similar when compared to observations in some studies from overseas. This probably 
results from a high caseload and lack of adequate space for hospitalization in the wards. Even though the national guidelines recommend retention of mothers after delivery in the hospitals for $48 \mathrm{~h}$ or more, bed availability can become an issue in the case of busy health facilities. Hence, infrastructural expansion in terms of providing more beds, and making the hospital stay more comfortable at primary health care levels, becomes critical. The absence of maternal complications is associated with early discharge, and women with complications are retained in hospitals for longer periods (Nipte et al., 2015).

Similar findings were reported in studies from New Delhi, India, and the United States. Relatives, family members, and mothers who had no complications during delivery need to be motivated to agree to stay in the hospitals after delivery for a minimum of 48 $\mathrm{h}$ to ensure an uneventful postpartum period. Additionally, the issue of early discharge is also decided by other socio-cultural factors. Elderly females in the family or close relatives or spouses of mothers need to be educated on delivery-related complications and the need for a $48 \mathrm{~h}$ hospital stay after the delivery. Various other reasons for seeking early discharge from hospitals may be: dissatisfaction about hospital accommodation or care, need to take care of other children at home, feeling more comfortable at home, reducing out of pocket expenditure due to longer hospitalization, perception of getting to know the baby better at home, preventing disturbance due to hospital routines, and desire to be close to the family. These reasons can be addressed through improving the hospital environment and allowing better and easy contact between the mothers and their families (Nipte et al., 2015).

It is important to emphasize that the medical risks to mothers and babies excessively outweigh the perceived benefits of early discharge, and Information Education Commu- nication (IEC) strategies need to focus on this. The mothers' level of education, income, parity, gestational age, and birth weight of babies, were not observed to be associated with early discharge. Similar observations concerning gestational age, infant birth weight, and parity were made in a study from the United States of America. 24 However, some other studies have reported contradictory observations (Nipte et al., 2015).

A systematic literature review similar to our study entitled vaginal delivery: how does early hospital discharge affect mother and child outcomes? Conducted by (Benahmed et al., 2017) concluded that the currently available literature provides little scientific evidence to guide postpartum discharge policy planning. The evidence-based randomized control trials (RCTs) are old, with the most recent trial published 10 years ago, and the quality of evidence of these trials is poor. The more recent evidence is based only on two very poor quality non-randomized studies (Benahmed et al., 2017)

Moreover, the concept of the early discharge itself is very variable across studies, leading to health outcomes being measured at variable times after delivery.

Despite these limitations, early discharge seems to be safe for both mother and newborn. Breastfeeding did not seem to be affected. Because of the lack of robust clinical evidence and full economic evaluations, the current data neither support nor discourage the widespread use of early postpartum discharge. Before implementing an early discharge policy, Western countries with longer lengths of hospital stays, such as France and Belgium, may benefit from testing shorter lengths of stay in studies with an appropriate design (e.g. randomized) (Benahmed et al., 2017; Brown et al., 2002).

In our study, the mothers who fail to attend the 7-day follow-up appointment, were con- 
sidered as lost to follow up. Whereas the México study recorded missed women as lost due to change of residence, failure to locate the place of residence after three attempts, or incorrect address. No significant differences were found between women who completed the study and those who were lost to followup, regarding the length of hospital stay, age, and the number of live-born children (Ramírez-Villalobos et al., 2009).

In another study in Sweden (Intrapartum and postpartum care in Sweden: women's opinions and risk factors for not being satisfied). The researchers found the following risk factors for not being satisfied were: age $<25$ years (intrapartum care only) elementary school (intrapartum and postpartum care), lack of support from a partner (intrapartum care); suffering from many physical symptoms (intrapartum and postpartum care); lack of support by a midwife (intrapartum care, only), dissatisfaction with the birth environment (intrapartum care only), insufficient time for breastfeeding support, encouragement and personal questions in postpartum care (Waldenström et al., 2006).

\section{CONCLUSIONS}

Late discharge mothers had received anesthesia and performed an episiotomy more than early discharge mothers. A complication of episiotomy was recorded more in mothers with early discharge than in late discharged mothers. History of thromboembolic complication after delivery and readmission to hospital after delivery was recorded only in mothers with an early discharge. A qualitative study for understanding the sociocultural grounding for early discharge is needed. Early discharge should be decided by senior physicians.

Financial support and sponsorship: Nil.

Conflicts of interest: There are no conflicts of interest.

\section{REFERENCES}

Benahmed, N., San Miguel, L., Devos, C., Fairon, N., \& Christiaens, W. (2017). Vaginal delivery: how does early hospital discharge affect mother and child outcomes? A systematic literature review. BMC pregnancy and childbirth, 17(1), 1-14.

Braveman, P., Egerter, S., Pearl, M., Marchi, K., \& Miller, C. (1996). Early discharge of newborns and mothers: a critical review of the literature. Pediatrics, 96(4), 716-726.

Britton, J. R., Britton, H. L., \& Beebe, S. A. (1994). Early discharge of the term newborn: a continued dilemma. Pediatrics, 94(3), 291-295.

Brown, S., Small, R., Argus, B., Davis, P. G., \& Krastev, A. (2002). Early postnatal discharge from hospital for healthy mothers and term infants. Cochrane Database of Systematic Reviews(3).

Bueno, J. A. S., Romano, M. R., Teruel, R. G., Benjumea, A. G., Palacín, A. F., González, C. A., \& Manzano, M. C. (2005). Early discharge from obstetricspediatrics at the Hospital de Valme, with domiciliary follow-up. American journal of obstetrics and gynecology, 193(3), 714-726.

Cunningham F, G., Gant, Norman F Leveno. \& Kenneth J Gi. (2001). Williams obstetrics, 21st edition. New York: McGraw Hill. .

Fikree, F. F., Ali, T., Durocher, J. M., \& Rahbar, M. H. (2004). Health service utilization for perceived postpartum morbidity among poor women living in Karachi. Social science \& medicine, 59(4), 681-694.

Fortney JA \& Smith JB: Measuring maternal morbidity (1999). In Safe motherhood initiatives: critical issues. Edited by 
Berer M, Ravindran TKS. London: Reproductive Health Matters 43-50.

Hellman, L., Kohl, S., \& Palmer, J. (1962). Early hospital discharge in obstetrics. The Lancet, 279(7223), 227-232.

Koblinsky, M., \& Tinker, A. (1994). Programming for safe motherhood: a guide to action. Health Policy and Planning, 9(3), 252-266.

Lieu, T. A., Braveman, P. A., Escobar, G. J., Fischer, A. F., Jensvold, N. G., \& Capra, A. M. (2000). A randomized comparison of home and clinic followup visits after early postpartum hospital discharge. Pediatrics, 105(5), 10581065.

M. Chama, A. E.-N., A. Idrisa, C. (2000). Caesarean morbidity and mortality at Maiduguri, Nigeria. Journal of obstetrics and gynaecology, 20(1), 4548.

Madden, J. M., Soumerai, S. B., Lieu, T. A., Mandl, K. D., Zhang, F., \& RossDegnan, D. (2002). Effects of a law against early postpartum discharge on newborn follow-up, adverse events, and HMO expenditures. New England Journal of Medicine, 347(25), 20312038.

Nipte, D., Dhayarkar, S., Pawar, S., Venkatsubramanian, S., \& Mehendale, S. (2015). Determinants of early discharge of mothers from hospitals after delivery in Beed block of Beed District, Maharashtra, India 2014. Clinical Epidemiology and Global Health, 3, S26-S33.

Norr, K. F., \& Nacion, K. (1987). Outcomes of postpartum early discharge, 1960-1986 A comparative review. Birth, 14(3), 135-141.
Organization, W. H. (1998). Postpartum care of the mother and newborn: a practical guide: report of a technical working group.

Ramírez-Villalobos, D., Hernández-Garduño, A., Salinas, A., González, D., Walker, D., Rojo-Herrera, G., \& HernándezPrado, B. (2009). Early hospital discharge and early puerperal complications. salud pública de méxico, 51, 212-218.

Silverton, L. (1993). The art and science of midwifery. Appleton \& Lange.

Waldenström, U., Rudman, A., \& Hildingsson, I. (2006). Intrapartum and postpartum care in Sweden: women's opinions and risk factors for not being satisfied. Acta obstetricia et gynecologica Scandinavica, 85(5), 551-560.

Waterstone, M., Wolfe, C., Hooper, R., \& Bewley, S. (2003). Postnatal morbidity after childbirth and severe obstetric morbidity. BJOG: An International Journal of Obstetrics \& Gynaecology, 110(2), 128-133.

Yaffe, M. J., Russillo, B., Hyland, C., Kovacs, L., \& McAlister, E. (2001). Better care and better teaching. New model of postpartum care for early discharge programs. Canadian Family Physician, 47(10), 2027-2033. 


\section{الخروج المبكر من المستثفى ومضاعفات النفاس المبكرة}

زاهية سعد الغزال 1، فاطمة عبدالهه امطول 20 واكرام بركات بن سعود3 3

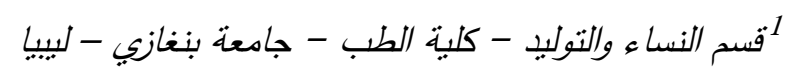

2قنس طب الاسرة والمجتدع - كليه الطب- جامعة بنغازي - لبييا

تاريخ الاستلام: 22 نوفمبر 2020/ تاريخ القبول: 30 ديسمبر 2020 1023 https://doi.org/10.54172/mjsc.v35i4.333:Doi

المستخلص : تهدف الدراسة إلى تقييم العلاقة بين وقت الخروج بعد الولادة، والأعراض التي تدل على حدوث مضاعفات خلال

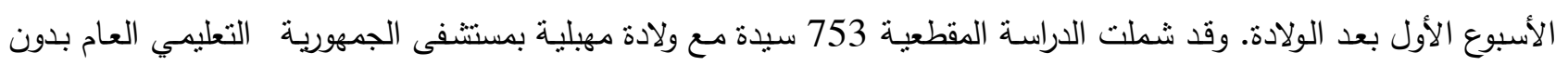

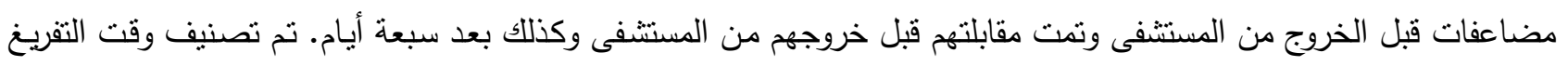

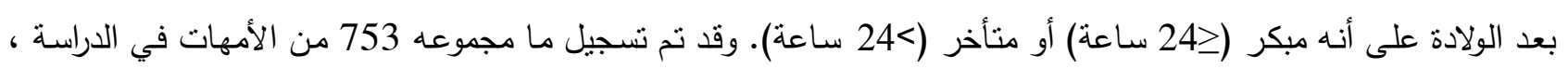

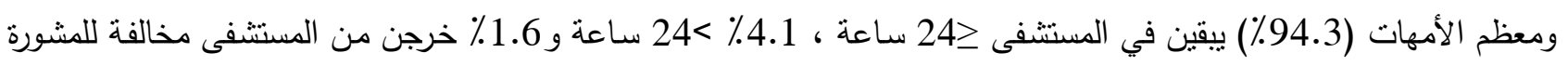

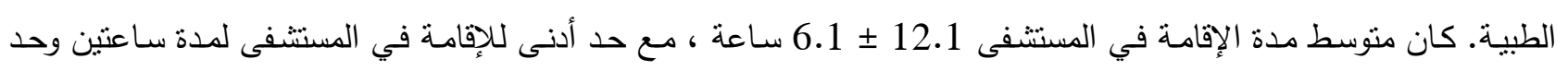

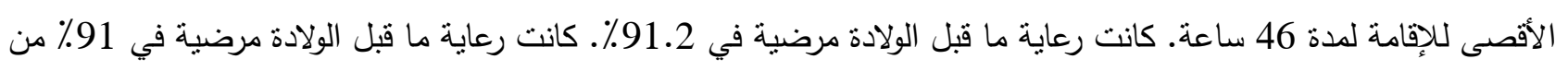

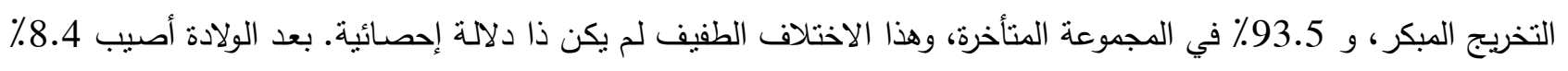

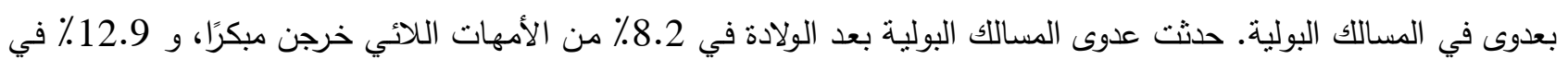

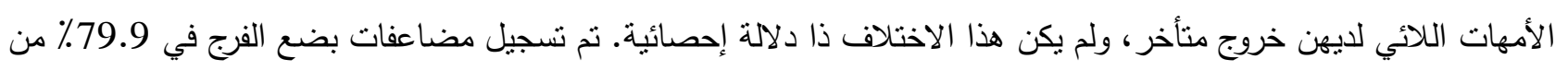

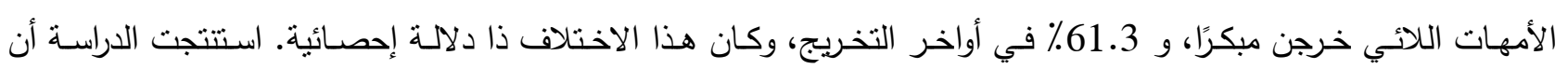

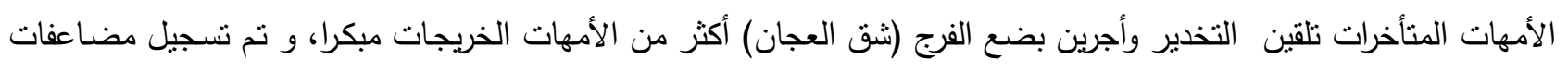

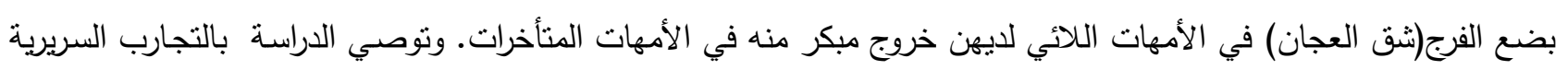

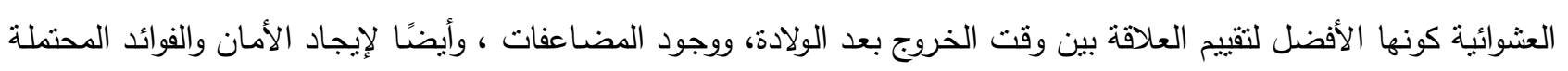
للإقامة القصيرة في المسنتفى. الكلمات المفتاحية: الخروج المبكر من المستشفى ، الولادة المهبلية ، مضاعفات النفاس. 